\title{
Pengaruh Customer Perceived Value Terhadap Word Of Mouth Dengan Customer Loyalty Sebagai Variabel Mediasi (Study Kasus Di CV Putra Putri)
}

\author{
Abdul Rohim ${ }^{1}$, Sonny Arvianto ${ }^{2}$ \\ STIE PGRI Dewantara Jombang \\ Abdulrohim1304@gmail.com, Sonny1261119.mjb@gmail.com
}

Diserahkan:18 Oktober 2016, Diterima: 24 April 2017

\begin{abstract}
This research aims to determine how much influence customer perceived value (X1) to word of mouth (Y2), customer perceived value (X1) to customer loyalty (Y1), customer loyalty (Y1) to word of mouth (Y2) and customer perceived value (X1) to word of mouth (Y2) mediated customer loyalty (Y1) on customer CVPutra Putri in Jombang district.This research uses a quantitative approach. The sample was 100 customerCVPutra Putri live in Jombang by using non-probability sampling method and sampling techniques saturated. The research instrument a questionnaire and analyzed using regression mediation analysis and sobel test. The results of this research indicate that the customer perceived value (X1) has an influence on word of mouth (Y2) with a significance value less than 0.05 is equal to 0.000 , customer perceived value (X1) has an influence on customer loyalty (Y1) with significant value less than 0.05 is equal to 0.017, customer loyalty (Y1) has an influence on word of mouth (Y2) with a significance value less than 0.05 is 0.003 and customer loyalty (Y1) mediated customer perceived value (X1) to word of mouth (Y2) with a p-value of less than 0.05 is equal to 0.001.Forasubsequent research examines other factors besides affecting customer perceived value of word of mouth in order to obtain more complete information about the factors that influence word of mouth.
\end{abstract}

Keywords : Customer perceived value, customer loyalty, word of mouth

\begin{abstract}
Abstrak
Penelitian ini bertujuan mengetahui seberapa besar pengaruh customer perceived value (X1) terhadap word of mouth (Y2), customer perceived value (X1) terhadap customer loyalty (Y1), customer loyalty (Y1) terhadap word of mouth (Y2) dan customer perceived value (X1) terhadap word of mouth (Y2) yang dimediasi customer loyalty (Y1) pada pelanggan CVPutra Putri di kabupaten Jombang. Penelitian ini menggunakan pendekatan kuantitatif. Sampel penelitian ini adalah 100 pelanggan CVPutra Putri yang berdomisili di kabupaten Jombang dengan menggunakan metode non probability sampling serta teknik sampling jenuh. Instrumen penelitian ini menggunakan kuesioner dan dianalisis menggunakan analisis regresi mediasidan uji sobel.Hasil penelitian ini menunjukkan bahwa customer perceived value (X1) memiliki pengaruh terhadap word of mouth (Y2) dengan nilai signifikansi lebih kecil dari 0,05 yaitu sebesar 0,000 , customer perceived value (X1) memiliki pengaruh terhadap customer loyalty (Y1) dengan nilai signifikansi lebih kecil dari 0,05 yaitu sebesar 0,017 , customer loyalty (Y1) memiliki pengaruh terhadap word of mouth (Y2) dengan nilai signifikansi lebih kecil dari 0,05 yaitu sebesar 0,003 dan customer loyalty (Y1) memediasi customer perceived value (X1) terhadap word of mouth (Y2) dengan nilai p-value sebesar lebih kecil dari 0,05 yaitu sebesar 0,001 .Untuk penelitian selanjutanya mengkaji faktor lain selain customer perceived value yang mempengaruhi word of mouth agar memperoleh informasi yang lebih lengkap tentang faktor-faktor yang mempengaruhi word of mouth.
\end{abstract}

Kata kunci : Nilai pelanggan dirasakan, loyalitas pelanggan, dari mulut ke mulut

\section{A. PENDAHULUAN}

Persaingan bisnis saat ini memperlihatkan kompetisi yang cukup ketat pada masing - masing industri yang terlihat semakin banyaknya jumlah industri yang 
menawarkan keunggulan yang berbeda satu dengan yang lainnya.Dalam menghadapi persaingan bisnis yang ketat, para pelaku bisnis dituntut untuk menemukan suatu strategi yang inovatif agar bisnis tersebut dapat bertahan. Salah satu strategi yang dapat dilakukan adalah Word of Mouth (WOM).Word of Mouth merupakan suatu komunikasi lisan dari satu orang ke orang lainnya diantara seseorang penerima dan seseorang komunikator yang bersifat non komersial mengenai suatu merek, produk atau jasa (Arndt's dalam Stokes and Lomax 2001).

CV. Putra Putri adalah salah satu produsen alat peraga edukatif (APE) yang berdomisili di Perum Candi Indah Blok G No 4 Jombang, Provinsi Jawa timur, pertumbuhan pelanggan dalam beberapa tahun terakhir mengalami penurunan. Hal ini menunjukkan bahwa perusahaan belum bisamenemukan suatu strategi yang inovatif dalam menghadapi persaingan agar dapat meningkatkan jumlah pelanggan yang nantinya akan menjadi pelanggan yang loyal pada perusahaan serta akan semakin meningkatnya omzet dikemudian hari yang akan dapat membuat perusahaan semakin berkembang, strategi yang relevan digunakan saat ini yaitu dengan strategi WOM karena tingkat kepercayaan dalam pengambilan keputusan pembelian produk dan jasa berasal dari rekomendasi konsumen lain. Hal ini sesuai penelitian yang di lakukan oleh Nielsen pada 50 negara di Eropa dan Asia Pasifik memperlihatkan bahwa WOM menjadi media pemasaran yang paling kuat dalam penjualan produk dan jasa. Enam dari sepuluh pasar teratas di Asia mengandalkan sebagai besar rekomendasi dari konsumen dimana tiga posisi teratas adalah Hongkong, Taiwan dan Indonesia. Lebih lanjut, hasil penelitian Hasan (2010) di Indonesia juga menunjukkan bahwa tingkat kepercayaan dalam pengambilan keputusan pembelian suatu produk atau jasa berasal dari rekomendasi konsumen lain yaitu sebesar $79 \%$.

Berdasarkan penelitian yang dilakukan oleh Matos dan Rossi (2008) ada beberapa antenseden WOM yaitu kepuasan, loyalitas, kualitas, komitmen, kepercayaan dan nilai pelanggan (perceived value). Hartline dan Jones (1996) mengusulkan bahwa nilai yang dirasakan pelanggan akan memberikan pengaruh pada WOM. Apabila pelanggan merasa bahwa mereka menerima nilai yang relatif tinggi, maka pelanggan cenderung lebih berkomitmen kepada suatu organisasi dan berusaha untuk merekomendasikan suatu produk atau jasa kepada kelompok referensinya agar menjadi lebih setia kepada organisasi yang sama.

Dalam penelitian ini peneliti ingin memberikan peran mediasi dari customer perceived value dengan WOM variabel mediasi yaitu customer loyalty karena dengan adanya pelanggan yang loyal maka peluang terciptanya word of mouth semakin besar hal ini sesuai penelitian yang di lakukan oleh Akbari,et al (2016) mengenai Relationship marketing and word of mouth communications : Examining the mediating role of customer loyalty mengungkapkan bahwa relationship marketing memiliki dampak positif yang signifikan terhadap customer loyalty yang menyebabkan peningkatan word of mouth hal ini menunjukkan bahwa customer loyalty memainkan peran mediasi antara relationship marketing dengan word of mouth.

Ada 4 (empat) rumusan masalah yang diangkat dalam penelitian ini yaitu: 1) ApakahCustomer Perceived Value Mempengaruhi WOM? 2) Apakah Customer Perceived Value Mempengaruhi Customer Loyalty?, 3) Apakah Customer Loyalty Mempengaruhi WOM?, 4) Apakah Customer Loyalty Memediasi Pengaruh Customer Perceived Value Terhadap WOM?

Dalam penelitian ini, batasan masalahnya adalah: 1) Untuk kajian mengenai nilai pelanggan (customer perceived value) peneliti memfokuskan pada 4 (empat) dimensi 
yaitu, nilai produk, nilai pelayanan, nilai personal dan nilai citra, 2) Untuk kajian mengenai customer loyalty peneliti memfokuskan pada repeat purchase, rentention, dan referalls, 3) Untuk kajian mengenai WOM peneliti memfokuskan pada kemampuan konsumen dalam membicarakan hal-hal positif tentang kesan dari perusahaan kepada orang lain, rekomendasi kualitas produk kepada orang lain, dan rekomendasi kulitas pelayaan perusahaan kepada orang lain dan 4) Tidak dilakukan pembahasan terhadap aspek selain yang berhubungan dengan customer perceived value, customer loyalty dan WOM .

Diharapkan, hasil dari penelitian ini bermanfaat bagi banyak pihak, khususnya perusahaan halini dapat digunakan sebagai masukan atau informasi bagi pengelola perusahaan untuk mengetahui dimensi dari customer perceived value yang berpengaruh terhadap word of mouth. Dan dapat digunakan sebagai bahan pertimbangan dalam menentukan langkah dan kebijakan perusahaan khususnya dalam penentuan strategi pemasaran yang berorientasi pada terciptanya word of mouth.

\section{B. LANDASAN TEORI \\ Pengertian Word Of Mouth}

WOM didefenisikan sebagai komunikasi satu orang dengan orang yang lain diantara seorang penerima dan komunikator yang tidak bersifat komersial pada suatu merek, produk atau layanan. Komunikasi yang terjadi antara komunikator dan penerima ini dapat bersifat secara langsung dengan tatap muka dan juga terjadi secara elektronik yaitu melalui internet (Buttle dalam Stiokes and Lomax 2001).WOM dipandang sebagai media yag lebih cepat yang dapat dipercaya dan dapat diandalkan dibandingkan dengan media pemasar yang lain. Hal ini disebabkan karena saat komunikator memberikan masukan dan rekomendasi kepada penerima, komunikator tersebut tidak memiliki kepentingan apapun pada produk, jasa atau merek tertentu.

Berdasarkan pendapat Rangkuti (2009), pesan yang disampaiakan melalui word of mouth dapat diukur dengan menggunakan indikator-indikator, yaitu dengan melihat hubungan antara lawan bicara mengenai produk $\mathrm{X}$ dan tindakan setelah melakukan pembicaraan mengenai produk $\mathrm{X}$ tersebut.

Babin, et al (2005) pada penelitiannya mengukur word of mouth dengan indicator: 1) Kemauan konsumen dalam membicarakan hal-hal positif tentang kesan dari perusahaan kepada orang lain, 2) Rekomendasi kualitas produk perusahaan kepada orang lain, 3) Rekomendasi kualitas pelayanan perusahaan kepada orang lain.

\section{Pengertian Customer Perceived Value}

Kotler dan Keller (2008) menyatakan bahwa nilai yang dipersepsikan pelanggan (customer perceived value) merupakan selisih antara penilaian pelanggan prospektif atas semua manfaat dan biaya dari suatu penawaran terhadap alternatifnya.Perusahaan perlu memperhatikan nilai yang akan di dapatkan pelanggan demi memuaskan pelanggan dan meningkatkan daya saing perusahaan. Kotler (1995) menjabarkan faktorfaktor yang dapat membentuk perceived value, yaitu :

1. Nilai produk(product value), terdiri dari : ciri atau fungsi produk (features), mutu kinerja (performance), mutu kesesuaian dengan spesefikasi (conformance to specifications), ketahanan (durability), design produk (aesthetics).

2. Nilai pelayanan (service value), terdiri dari : pengiriman, kemampuan memberikan layanan (reliabilitas), pelatihan pelanggan, dan perbaikan (responsivitas).

3. Nilai personal (personel value), terdiri dari kompeten, sopan, kredibilitas, dapat diandalkan. 
4. Nilai citra (image value), terdiri dari merek, karateristik karyawan, progam perusahaan.

\section{Pengertian Customer Loyalty}

Loyalitas konsumen menurut Reichheld (1996, dalam East et al.,2000) merupakan tingkatan dimana konsumen akan tetap menggunakan suatu merekatau produsen tertentu. Adanya loyalitas pelanggan akan suatu produk atau jasa, dapat memberikan perlindungan bagi perusahaan dari persaingan dan memberikan lebih banyak kontrol dalam membuat rencana program-program pemasaran yang akandijalankan oleh perusahaan tersebut. Sementara menurut Oliver (1993, dalam Yin Lam et al., 2004), loyalitas konsumen didefinisikan sebagai komitmen pembeli terhadap suatu produk, jasa, merek, atau organisasi.Menurut Kotler \& Keller (2006) indikator loyalitas pelanggan adalah :

1. Repeat purchase (kesetiaan terhadap pembelian produk).

2. Retention (ketahanan terhadap pengaruh yang negatif mengenai perusahaan)

3. Referalls (mereferensikan secara total esistensi perusahaan)

\section{Hubungan Antara Customer Perceived Value Dengan WOM}

Hartline dan Jones (1996) juga menyatakan bahwa nilai yang dirasakan pelanggan akan memberikan pengaruh terhadap pada WOM. Apabila pelanggan merasa bahwa mereka menerima nilai yang relatif tinggi, maka pelanggan merasa menerima nilai yang relatif tinggi, maka pelanggan cenderung lebih berkomitmen kepada suatu organisasi dan berusaha untuk merekomendasi suatu produk atau jasa kepada kelompok referensinya agar menjadi lebih setia kepada organisasi yang sama.

\section{Hubungan Antara Customer Perceived Value Dengan Customer Loyalty}

Hubungan antara customer perceived value dengan word of mouth dinyatakan berdasarkan hasil penelitian berdasarkan hasil uji hipotesis, dapat diketahui bahwa Customer Value dari konsumen Bandar Jakarta Surabaya memiliki pengaruh yang signifikan terhadap Customer Loyalty yang memiliki arti bahwa jika Customer Value yang dirasakan konsumen semakin tinggi atau semakin baik, maka loyalitas atau Customer Loyalty juga akan mengalami peningkatan yang signifikan.

\section{Hubungan Antara Customer Loyalty Dengan Word of Mouth}

Hubungan antara customer loyalty dengan word of mouth dinyatakan berdasarkan hasil penelitian yang di lakukan Zikra et al (2013) mengenai Pengaruh Customer Loyalty terhadap teriptanya Word of Mouth Communication dalam penelitiannya menjelaskan bahwa Customer Loyalty mempengaruhi terciptanya volume Word of Mouth Communication. Hal ini diartikan bahwa jika tingkat Customer loyalty yang semakin tinggi, maka tingkat tercipnya Word of Mouth Communicatiaonakan semakin tinggi dan signifikan

\section{Hubungan Antara Customer Perceived Value Dengan WOM melalui Customer Loyalty}

Kazemi dan Haddadi (2016) mengenai Relationship marketing and word of mouth communications : Examining the mediating role of customer loyalty mengungkapkan bahwa relationship marketing memiliki dampak positif yang signifikan terhadap customer loyalty yang menyebabkan peningkatan word of mouth hal ini menunjukkan bahwa customer loyalty memainkan peran mediasi antara relationship marketing dengan word of mouth.

\section{Kerangka Konseptual}

Dalam penelitian ini terdapat tiga variabel yang akan diteliti, yaitu customer perceived value sebagai variabel independen, word of mouth sebagai variabel dependen, dan 
customer loyalty sebagai variabel mediasi, kerangkan konseptual dalam penelitian ini adalah sebagai berikut :

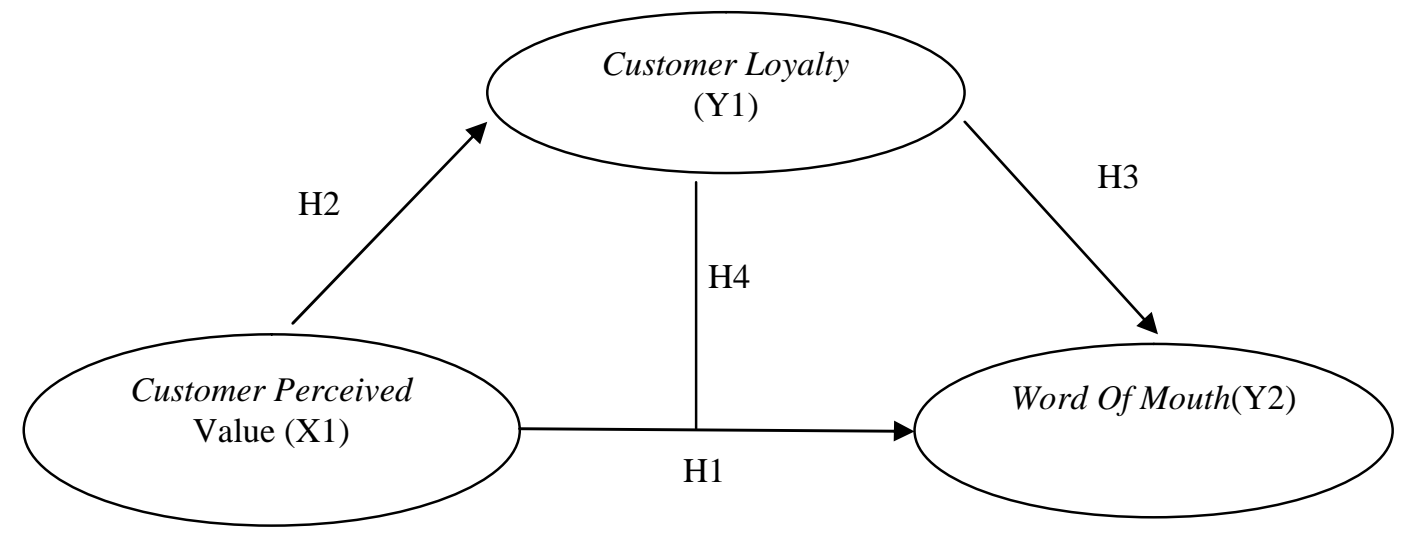

Gambar 1: Kerangka Konseptual

\section{Hipotesis}

H1 : Ada pengaruh positif Nilai Pelanggan terhadap Word Of Mouth

$\mathrm{H} 2$ : Ada pengaruh positif Nilai Pelanggan terhadap Loyalitas Pelanggan

H3 : Ada pengaruh positif Loyalitas Pelanggan terhadap Word Of Mouth

H4 : Loyalitas Pelanggan memainkan peran mediasi antara Nilai Pelanggan dan

Word Of Mouth

\section{METODE PENELITIAN \\ Jenis Penelitian}

Penelitian ini merupakan jenis penelitian verifikatif dengan menggunakan metode penelitian eksplanasi (Explanatory Research) dimana sebuah penelitian eksplanatori menurut Singarimbun dalam Singarimbun dan Effendi (2006) merupakan penelitian yang menjelaskan hubungan klausul antara variabel penelitian dengan pengujian hipotesa.

\section{Populasi Dan Sampel}

Populasi penelitian adalah seluruh pelanggan CV. Putra Putri. Jumlah pelanggan CV. Putra Putri yaitu 231 pelanggan, jumlah pelanggan tersebut mencakup di semua daerah pemasaran yaitu seluruh wilayah Indonesia dan ekspor ke Switzerland, dalam penelitian ini di fokuskan hanya pelanggan yang ada di kabupaten Jombang jadi untuk populasi penelitian ini adalah sebesar 100 pelanggan CV. Putra Putri yang berdomisili di kabupaten Jombang.

Teknik penarikan sampel yang digunakan dalam penelitian, menggunakan teknik sampling jenuh yaitu penentuan sampel bila semua anggota populasi digunakan sebagai sampel (Sugiyono, 2014).Sampel yang diambil dari penelitian ini adalah 100 pelanggan CVPutra Putri di kabupaten Jombang.

\section{Teknik Pengumpulan Data dan Skala Pengukuran}

Teknik pengumpulan data yang digunakan dalam penelitian ini adalah observasi, angket, dokumentasi dan wawancara.

Skala pengukuran menggunakan skala pengukuran ordinal yaitu memberikan informasi tentang jumlah relatif karateristik yang berbeda yang dimiliki oleh obyek atau individu tertentu. Dan di dalam angket menggunakan skala likert yang terdapat 5 (lima) 
poin kriteria jawaban mulai dari sangat positif (skor lima) hingga sangat negatif (skor satu)

\section{Uji Instrumen}

Istrumen penelitian yang digunakan adalah kuiseoner, agar data yang diperoleh mempunyai tingkat akurasi dan konsistensi yang tinggi, instrumen penelitian yang digunakan harus valid dan reliabel (Sanusi, 2011).Uji instrumen yang digunakan yaitu uji validitas dan uji reliabilitas.

Hasil uji validatas dan uji reliabilitas mengenai disetiap indikator variabel penelitian, untuk uji validitas dapat diketahui bahwa nilai korelasi ( $\mathrm{r}$ hitung) lebih besar dari $\mathrm{r}$ tabel $(0,312)$ dan untuk melihat reliabilitasnya dapat diketahaui dari nilai cronbach'calpha lebih besar dari 0,600 sehingga dapat disimpulkan semua item pertanyaan semua indikator variabel dinyatakan valid dan reliabel dan dapat digunakan untuk penelitian selanjutnya.

\section{Teknik Analisi Data}

1. Deskriptif Kuantitatif. Analisis deskriptif digunakan untuk menggambarkan frekuensi masing-masing item variabel dengan kategori rata-rata skor dari responden.Untuk mengetahui atau menentekan kategori jawaban responden dari masing-masing variabel tergolong tinggi, sedang atau rendah maka ditentukan skala intervalnya dengan cara sebagai berikut:

$$
\begin{array}{ll}
\text { Skor tertinggi - Skor terendah } & =5-1 \\
\text { Rentang Skor } & =0,8
\end{array}
$$

Sehingga dengan demikian dapat diketahui kategori jawaban responden masingmasing variabel yaitu :
a. Skor untuk kategori sangat tinggi $: 4,21-5,00$
b. Skor untuk kategori tinggi : $3,41-4,20$
c. Skor untuk kategori sedang $\quad: 2,61-3,40$
d. Skor untuk kategori rendah $\quad: 1,81-2,60$
e. Skor untuk kategori sangat rendah : $1,00-1,80$

2. Analisis Regresi Mediasi. Analisis regresi mediasi ini digunakan untuk mengetahui dan memperoleh gambaran mengenai pengaruh customer perceived value (X1), terhadap WOM (Y2) dengan customer loyalty (Y1) sebagai variabel mediasi. Analisis dalam penelitian ini menggunakan dua metode untuk menunjukkan serangkaian persyaratan yang harus di penuhi untuk model mediasi. Seperti diuraikan oleh Baron dan Kenny (1986).

3. Uji Hipotesis. Untuk menguji hipotesis yang telah diajukan dan untuk menguji pengaruh variabel mediasi dalam memediasi variabel independen terhadap variabel dependen.

4. Uji Sobel. Uji sobel Adalah untuk mengetahui pengaruh variabel mediasi yaitu dengan uji sobel.Menurut Baron \& Kenny (1986) suatu variabel disebut variabel mediasi jika variabel tersebut ikut mempengaruhi hubungan antara variabel independet dan variabel dependen.Pengujian hipotesis mediasi dapat dilakukan dengan prosedur yang dikembangkan oleh Sobel (1982) dan dikenal dengan Uji Sobel (Sobel Test).

5. Uji Determinasi. Koefisien determinasi digunakan untuk menunjukkan seberapa besar pengaruh variable independen terhadap variable dependen, maka dihitung 
koefisien determinasi (Kd) dengan asumsi faktor-faktor lain diluar variabel dianggap konstan/tetap (cateris paribus).

\section{HASIL PENELITIAN DAN PEMBAHASAN Analisis Uji Regresi Mediasi}

Analisi regresi mediasi digunakan untuk melihat pengaruh variabel independen terhadap variabel dependen.Untuk mengetahui apakah model regresi dapat digunakan untuk memprediksi variabel dependen. Jika nilai signifikansi berada di bawah 0,05 maka model regresi dapat digunakan untuk mempredikasi variabel dependen. Berikut hasil uji analisis regresi mediasi :

Tabel 1:Hasil Uji Regresi Mediasi

\begin{tabular}{lc|c|ccc}
\hline \multicolumn{1}{c}{ Variabel Independen } & $\begin{array}{c}\text { Koefesien } \\
\text { Regresi }\end{array}$ & $\begin{array}{c}\text { Standart } \\
\text { Error }\end{array}$ & Nilai T & Sig. & $\begin{array}{c}\text { Signifikasi } \\
\text { Hubungan }\end{array}$ \\
\hline Constanta & $4.274^{*}$ & $1.508^{*}$ & $2.834^{*}$ & $0,006^{*}$ & \\
\hline Customer Perceived Value & $0,436^{*}$ & $0,024^{*}$ & $4.790^{*}$ & $0,000^{*}$ & Signifikan \\
\hline Constanta & $8.822^{*}$ & $0,883^{*}$ & $9.992^{*}$ & 0,000 & \\
\hline Customer Loyalty & $0,294^{*}$ & $0,076^{*}$ & $3.051^{*}$ & $0,003^{*}$ & Signifikan \\
\hline Constanta & $6.225^{* *}$ & $2.054^{* *}$ & $3.031^{*}$ & $0,003^{* *}$ & \\
\hline Customer Perceived Value & $0,239^{* *}$ & $0,033^{* *}$ & $2.436^{* *}$ & $0,017^{* *}$ & Signifikan \\
\hline * Variabel dependen word of mouth & & & & \\
'** Variabel dependen customer loyalty & & & & \\
\hline
\end{tabular}

Sumber: Data primer diolah, 2015

Berdasarkan diatasmenunjukkan bahwa nilai sig. di variabel independen lebih kecil dari $\alpha(0,05)$, maka dapat dinyatakan model regresi dapat digunakan untuk memprediksi variabel dependen

\section{Analisis Uji Hipotesis}

Tabel 2: Hasil Uji Hipotesis

\begin{tabular}{clllc}
\hline Hipotesis & \multicolumn{1}{c}{ Keterangan } & Nilai t & Sig. & $\begin{array}{c}\text { Penerimaan } \\
\text { Hipotesis }\end{array}$ \\
\hline H1 & $\begin{array}{l}\text { Ada pengaruh positif Nilai Pelanggan } \\
\text { terhadap Word Of Mouth }\end{array}$ & 4.790 & 0,000 & Diterima \\
\hline H2 & $\begin{array}{l}\text { Ada pengaruh positif Nilai Pelanggan } \\
\text { terhadap Loyalitas Pelanggan }\end{array}$ & 2.436 & 0,017 & Diterima \\
\hline H3 & $\begin{array}{l}\text { Ada pengaruh positif Loyalitas } \\
\text { Pelanggan terhadap Word Of Mouth }\end{array}$ & 3.051 & 0,003 & Diterima \\
\hline
\end{tabular}

Sumber: Data primer diolah, 2015

Berdasarkan tabel diatas hipotesis yang pertama mengenai adanya pengaruh customer perceived value (nilai pelanggan) terhadap word of mouth(WOM), hal ini dibuktikan dengan nilai signifikansi lebih kecil dari 0,05 yaitu sebesar 0,000 sehingga terdapat pengaruh antara customer perceived value terhadap word of mouth. Dapat disimpulkan bahwa hipotesis pertama dalam penelitian ini diterima.

Hipotesis kedua mengenai adanya pengaruh customer perceived value (nilai pelanggan) terhadap customer loyalty (loyalitas pelanggan), hal ini dibuktikan dengan nilai signifikansi lebih kecil dari 0,05 yaitu sebesar 0,017 sehingga terdapat pengaruh antara customer perceived value terhadap customer loyalty (loyalitas pelanggan). Dapat disimpulkan bahwa hipotesis kedua dalam penelitian ini diterima.

Hipotesis ketiga mengenai adanya pengaruh customer loyalty (loyalitas pelanggan) terhadap word of mouth (WOM), hal ini dibuktikan dengan nilai signifikansi lebih kecil dari 0,05 yaitu sebesar 0,030 sehingga terdapat pengaruh antara customer 
loyalty terhadap word of mouth. Dapat disimpulkan bahwa hipotesis ketiga dalam penelitian ini diterima

\section{Analisis Uji Determinasi $\left(R^{2}\right)$}

Tabel 3: Hasil Uji Determinasi

\begin{tabular}{c|cccc}
\hline Model & R & R Square & Adjusted R Square & $\begin{array}{c}\text { Std. Error of the } \\
\text { Estimate }\end{array}$ \\
\hline 1 & 0,436 & 0,190 & 0,181 & 2.078 \\
\hline 2 & 0,294 & 0,087 & 0,077 & 2.207 \\
\hline 3 & 0,239 & 0,057 & 0,047 & 2.831 \\
\hline
\end{tabular}

Model 1 Dependen word of mouth, Independen customer perceived value.

Model 2 Dependen word of mouth, Independen customer loyalty.

Model 3 Dependen customer loyalty, Independen customer perceived value

Sumber: Data primer diolah, 2015

Berdasarkan table diatas terlihat bahwa model 1 (satu) $\mathrm{R}$ square sebesar 0,190 atau $19 \%$ atau dalam kategori cukup berpengaruh, angka ini menunjukkan bahwa variabilitas word of mouth bisa menjelaskan variabel customer perceived value, yaitu prosentasenya hanyasebesar $19 \%$ sedangkan sisanya $81 \%$ dipengaruhi oleh faktor faktor lain diluar model regresi.

Model 2 (dua) terlihat bahwa $\mathrm{R}$ square sebesar 0,087 atau 8,7 \% atau dalam kategori rendah tapi pasti ada berpengaruh, angka ini menunjukkan bahwa variabilitas word of mouth bisa menjelaskan variabel customer perceived value prosentasenya hanyasebesar 5,7 \% sedangkan sisanya 94,3\% dipengaruhi oleh faktor - faktor lain diluar model regresi.

Model 3 (tiga) terlihat bahwa $\mathrm{R}$ square sebesar 0,057 atau 5,7 \% atau dalam kategori rendah tapi pasti ada berpengaruh, prosentasenya hanyasebesar 5,7 \% sedangkan sisanya 94,3\% dipengaruhi oleh faktor - faktor lain diluar model regresi

\section{Analisi Uji Sobel}

Dalam hal ini ingin menguji hipotesis yang ke empat yaitu customer loyalty (loyalitas pelanggan) memainkan peran mediasi antara customer perceived value (nilai pelanggan) dan word of mouth. Berikut hasil uji sobel.

Tabel4: Hasil Uji Sobel

\begin{tabular}{|c|c|c|c|c|}
\hline & \multicolumn{2}{|c|}{ Input Data } & \multicolumn{2}{|c|}{ Test statistic } \\
\hline \multirow{4}{*}{$\begin{array}{c}\text { Customer } \\
\text { Perceived Value }\end{array}$} & A & 0,239 & Indirect Effect & 0,070 \\
\hline & B & 0,294 & Total Effect & 0,730 \\
\hline & $\mathrm{Sa}$ & 0,033 & Sobel Test (z-value) & 3,412 \\
\hline & $\mathrm{Sb}$ & 0,076 & p-value & 0,001 \\
\hline & $\begin{array}{l}\text { Next I } \\
\text { Indir }\end{array}$ & $\begin{array}{l}\text { Ton Fo } \\
\text { Total }\end{array}$ & Result & Mediation \\
\hline & $\frac{\mathrm{C}}{\mathrm{Sig}(\mathrm{c}}$ & $\frac{0,436}{0}$ & Type Of Mediation & Partial Mediation \\
\hline
\end{tabular}

Sumber: Data primer diolah, 2015

Berdasarkan table diatas mengenai hasil uji sobel, berdasarkan hipotesis yang keempat mengenai customer loyalty (loyalitas pelanggan) memainkan peran mediasi antara customer perceived value (nilai pelanggan) dan word of mouth, hal ini dibuktikan dengan nilai p-value lebih kecil dari 0,05 yaitu sebesar 0,001 sehingga terdapat pengaruh mediasi varibel customer loyalty antara customer perceived value terhadap word of mouth. Type mediasi yaitu mediasi partial artinya untuk terbentuknya word of mouth bisa melalui variabel mediasi (customer loyalty) atau bisa langsung tanpa 
memelalui variabel mediasi.Dapat disimpulkan bahwa hipotesis keempat dalam penelitian ini diterima.

\section{H1 = Pengaruh Customer Perceived Value Terhadap Word Of Mouth}

Customer perceived value merupakan persepsi dari pelanggan atas nilai yang diberikan oleh perusahaan, pelanggan mengharapkan nilai yang diberikan oleh peruahaan sesuai dengan yang diharapkan begitu juga perusahaan juga mengharapkan nilai yang diberikan akan memberikan dampak yang positif dari pelanggan. Hasil penelitian yang dilakukan oleh peneliti menunjukkan bahwa customer perceived value memiliki pengaruh terhadap word of mouth, dalam penelitiannya menjelaskan bahwa semakin tinggi customer perceived value semakin tinggi pula terciptanya WOM. Sehingga perlu untuk terus meningkatkan customer perceived value agar dapat memberikan jasa, produk, pelayanan dan citra yang baik kepada konsumen sehingga terbentuknya word of mouth. Dapat diartikan bahwa customer perceived value mempunyai peran penting dalam terbentuknya word of mouth.

Penelitian ini sesuai dengan penelitian yang dilakukan Sihaloho (2012) mengenai pengaruh customer perceived value terhadap WOM pelanggan Garuda Indonesia (study pelanggan di Depok) dalam penelitiannya menjelaskan bahwa customer perceived value memiliki pengaruh terhadap WOM

\section{H2 = Pengaruh Customer Perceived Value Terhadap Customer Loyalty}

Customer perceived value memiliki pengaruh terhadap customer loyalty hal ini ditunjukkan dari mayoritas respon yang disampaikan oleh responden terhadap item pertanyaan yang mendukung customer perceived value pada CVPutra Putri yaitu menunjukan respon yang positif dari customer perceived value terhadap Customer Loyalty yang dinyatakan oleh pelanggan bahwa pelanggan akan mengatakan hal positif mengenai perusahaan kepada orang lain, merekomendasikan kepada orang lain dan akan melakukan kebali untuk membeli ke perusahaan. Sehingga perlu untuk terus meningkatkan Customer Value agar dapat memberikan jasa dan pelayanan yang baik kepada konsumen sehingga mereka dapat terus loyal.

Hasil ini juga mendukung penelitian terdahulu yang dilakukan oleh Atalik dan Arslan (2009) bahwa Customer Value sangat mempengaruhi loyalitas konsumen.Penelitian ini dilakukan di restoran Bandar Jakarta Surabaya.

\section{H3 = Pengaruh Customer Loyalty Terhadap Word Of Mouth}

Customer loyalty memiliki pengaruh terhadap word of mouth hal ini diartikan bahwa jika tingkat customer loyalty yang semakin tinggi, maka tingkat terciptanya mord of mouthakan semakin tinggi dan signifikan. Sehingga perusahaan perlu untuk terus meningkatkan customer loyalty agar mendapatkan kesetiaan pelanggan dengan adanya repeat purchase, retention, referalls yang nantinya akan terbentunya word of mouth.

Hasil ini mendukung hasil penelitian yang di lakukan Zikraet al(2013) mengenai Pengaruh customer loyalty terhadap teriptanya word of mouth Communication dalam penelitiannya menjelaskan bahwa customer loyalty mempengaruhi terciptanya volume word of mouth communication.

\section{H4 = Customer Loyalty Memainkan Peran Mediasi Antara Customer Perceived Value dan Word Of Mouth}

Customer loyalty memiliki peran mediasi antara customer perceived value dan word of mouth yang berarti semakin tinggi customer perceived value akan mengakibatkan semakin tinggi pula customer loyalty dan secara tidak langsung akan mengakibatkan semakin tinggi pula word of mouth. 
Hasil ini sesuai dengan penelitian yang dilakukan Akbariet al(2016) mengenai Relationship marketing and word of mouth communications : Examining the mediating role of customer loyalty mengungkapkan bahwa relationship marketing memiliki dampak positif yang signifikan terhadap customer loyalty yang menyebabkan peningkatan word of mouth hal ini menunjukkan bahwa customer loyalty memainkan peran mediasi antara relationship marketing dengan word of mouth.

\section{E. PENUTUP}

Berdasarkan hasil penelitian diperoleh beberapa kesimpulan, yaitu: 1) Customer perceived value memiliki pengaruh positif terhadap word of mouth karena nilai signifikansi lebih kecil dari 0,05 yaitu sebesar 0,000,2) Customer perceived value memiliki pengaruh positif terhadap customer loyalty karena nilai signifikansi lebih kecil dari 0,05 yaitu sebesar 0,017, 3) Customer loyalty memiliki pengaruh positif terhadap word of mouth, dengan nilai signifikansi lebih kecil dari 0,05 yaitu sebesar $0,003,4$ ) Customer loyalty memediasi customer perceived value pada word of mouth, dengan nilai p-value sebesar lebih kecil dari 0,05 yaitu sebesar 0,001 .

Peneliti menilai varibel customer perceived value dalam terciptanya word of mouth mempunyai pengaruh yang yang positif dan sisanya dipengaruhi oleh faktor lain yang mempengaruhi terjadinya word of mouth pada pelanggan CV. Putra Putri faktor lain seperti kepuasan, kualitas, komitmen, kepercayaan dalam membentuk word of mouth.

Berdasarkan simpulan diatas, maka disarankan kepada perusahaan untukmeningkatkan nilai produk, nilai pelayanan, nilai personal dan nilai citra karena penilaian dari responden masih dalam rentang "tinggi" dan belum "sangat tinggi", sehingga perusahaan meningkatkan nilai-nilai tersebut agar nilai yang diberikan kepada pelanggan benar-benar bisa dirasakan pelanggan.

\section{DAFTAR PUSTAKA}

Arikuntoro, Suharsinmi. (1996). Prosedur Penelitian : Suatu Pendekatan Praktik, Edisi Revisi. Cetakan Ketigabelas. Rineka Cipta : Jakarta

Atalik, Ozlem dan Melike Arslan (2009). A Study to Determine the Effect of Customer Value on Customer Loyalty in Airline Companies Operating: Case of Turkish Air Travellers, International Journal of Business and Management Vol 4, Number 3.

Augusto, de Matos Celso \& Vargas, Rossi Carlos Alberto (2008). Word -of - mouth communications in marketing: a meta-analytic review of the antecedents and moderator. Pp. 36: 578 -596, New York.

Babin, Barry J; L,Yong-Kie, Kim,Eun-Fu; dan Griffin, Mitch (2005). Modeling Consumer Satisfaction and word of mouth: restaurant Patronage Korea. "Journal of Service Marketing, Vol 19, pp 133 - 139

Baron, R.M and Kenny, D.A (1986). The Moderator-Mediator Variable Distinction in Social Psychological research: Conceptual, Strategic and Statistical Consideration. Journal of personality and Social Psychology, 51 (6), 1173 - 1182 
Cindy Amylia kesumawardani (2012). Pengaruh servicescape dalam membentuk word of mouth (studi pada Restoran Marche Cabang Plaza Senayan).

Hasan, Ali (2010). Marketing Mulut ke mulut, cetakan ke - 1, Media Pressindo : Yogyakarta

Hartline, M.D dan Jones, K.C (1996). Employee performance cues in a hotel service environtment: influence on perceived service quality, value and word of mouth intentions. Journal of Business research, 35 (03), 207 - 215

Hughes, Mark. (2005). Buzz marketing : Get People To Talk About Your Staff. Portfolio : USA

Holbrook, Morris B.(1999). Consumer Value : A framework for analysis and research. London and New York Routledge ; USA

Ifka Desy A. Sihaloho (2012). Pengaruh customer perceived value terhadap WOM pelanggan Garuda Indonesia (studi pelanggan di Depok)

Lomax, W \& Stokes, D (2002). Taking Control of Word of Mouth Marketing: the case of entrepreneurial hotelier. Journal of small Business And Entreprise Development, 9,4 349-357. http://eprints.kingston.ac.uk/540

Kotler, Philip.,\& Kevin Lane Keller (2008). Marketing Management. 13 Edition. New Jersey : Pearson Prentice Hall

Mohsen Akbari, Reza Kazemi, Masoomeh Haddadi (2016). Relationship marketing and word of mouth communications : Examining the mediating role of customer loyalty

Oliver, Richard, 1993. A Coceptual Model Of Service Quality and Service Satisfaction; Compatible Goal, Different Concept, in advance in Service Marketing and management, vol 2; p $65-85$

Rangkuti, Freddy (2009). Strategi Promosi yang kreatif dan analisis kasus integrated Marketing Communication. Jakarta: PT Gramedia Pustaka Utama

Reichheld, F.F (1996), The Loyalty Effcect, Harvard Business School Press, Boston, M.A

Ruiz-molina, Mara-eugenia., \& Gil-saura, Irene. (2008). Perceived Value, Customer Attitude and Loyalty in Retailling. Journal of Retail and Leisure Property.

Sanusi, Anwar, 2011. Metode Penelitian Bisnis, Salemba Empat, Jakarta

Sugiyono.(2008). Metode Penelitian Kuantitatif, Kualitatif dan R\&D. Bandung: Alfabeta. 
Sobel, M.E 1982. Asymptotic Intervavals for Indirect Effects in structural Equations Models. In S. Leinhart (Ed), Sociological Methodology 1982 (pp. 290 - 312). San Fransisco: Jossey - Bass. http://quantpsy.org/sobel/sobel.htm

Swenney, Jilian C., Soutar, Geoffrey N. (2001). Customer perceived value : The development of a multiple item scale, Journal of Retailing.

Silverman, George. (2001). The Secrets of Word of Mouth Marketing : How to Triger Exponential Sales Through Runaway Word of Mouth. AMACOM : New York

Sernovitz, Andy. (2006). Word of Mouth Marketing : How Smart Companies Get People Talking. Kaplan Publishing : New York 